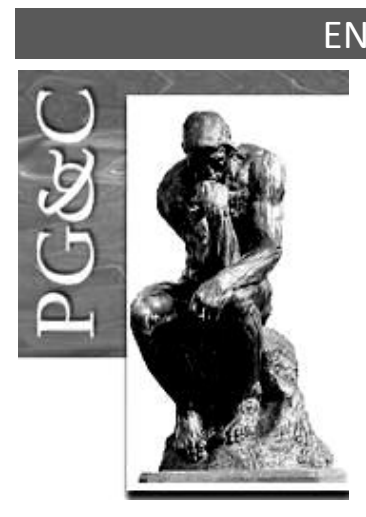

ENTREVISTA

\title{
REFLEXÕES SOBRE O ESTADO DA ARTE DA GESTÃO DA INFORMAÇÃO E DO CONHECIMENTO POR EMEIDE NÓBREGA DUARTE
}

\author{
Luciana Ferreira da Costa \\ Doutora em História e Filosofia da Ciência pela Universidade de Évora, \\ Portugal. Professora da Universidade Federal da Paraíba, Brasil. \\ E-mail: lucianna.costa@yahoo.com.br \\ Jorge de Oliveira Gomes \\ Mestre em Informática pela Universidade Federal de Campina Grande, \\ Brasil. Professor da Universidade Federal da Paraíba, Brasil. \\ E-mail: prof.jorgeogomes@gmail.com \\ Emeide Nóbrega Duarte \\ Doutora em Administração pela Universidade Federal da Paraíba, Brasil. \\ Professora da Universidade Federal da Paraíba, Brasil. \\ E-mail: emeide@hotmail.com

\section{Marta Lígia Pomim Valentim} \\ Doutora em Ciências da Comunicação pela Universidade de São Paulo, \\ Brasil. Professora da Universidade Estadual Paulista Júlio de Mesquita \\ Filho, Brasil. \\ E-mail: valentim@valentim.pro.br
}

\begin{abstract}
Resumo
Apresenta entrevista concedida pela Professora Doutora Emeide Nóbrega Duarte. A entrevistada é professora da Universidade Federal da Paraíba com atuação junto ao Departamento de Ciência da Informação e junto ao Programa de Pós-Graduação em Ciência da Informação desta universidade. 0 percurso formativo da entrevistada perpassa por graduação e mestrado em Biblioteconomia pela Universidade Federal da Paraíba e doutorado em Administração pela mesma universidade. Possui Pósdoutorado em Ciência da Informação pela Universidade Estadual Paulista Júlio de Mesquita Filho. Na entrevista, a Professora Emeide discorre sobre sua trajetória profissional consolidada no ensino superior e sobre a sua atuação na construção de conhecimento no âmbito da Ciência da Informação, particularmente no que se refere aos temas gestão da informação e gestão do conhecimento, temas em que detém vasta produção científica publicada em livros, artigos e comunicação em eventos. A trajetória e atuação evidenciam sua importância para o avanço do status quo da gestão da informação e da gestão do conhecimento no contexto nacional.
\end{abstract}

Palavras-chave: Gestão da Informação. Gestão do Conhecimento. Ciência da Informação. Universidade Federal da Paraíba.

\section{REFLECTIONS ABOUT THE STATE OF THE ART OF INFORMATION AND KNOWLEDGE MANAGEMENT BY EMEIDE NÓBREGA DUARTE}

\section{Abstract}

Presents an interview with Professor Emeide Nóbrega Duarte. The interviewee is professor in the Federal University of Paraiba, research in the Department of Information Science and in the Post Graduate Program in Information Science at this university. Has a degree and a master's degree in Library Science

Perspectivas em Gestão \& Conhecimento, João Pessoa, v. 8, n. 2, p. 194-204, mai./ago. 2018. DOI: http://dx.doi.org/10.21714/2236-417X2018v8n2p194

http://periodicos.ufpb.br/ojs2/index.php/pgc. ISSN: 2236-417X. Publicação sob Licença (cc) EY-NC-ND 
by the Federal University of Paraiba. She holds a PhD in Business Administration by the Federal University of Paraiba and holds a postdoctoral degree in Information Science from Universidade Estadual Paulista Júlio de Mesquita Filho. In the interview, Professor Emeide discusses her consolidated professional career in higher education and her role in the construction of knowledge in the field of Information Science, particularly in the areas of information management and knowledge management, subjects in which she holds scientific production published in books, articles and communication in events. The trajectory and performance show its importance for advancing the status quo of information management and knowledge management in the national context.

Keywords: Information management. Knowledge management. Information Science. Federal University of Paraiba.

\section{APRESENTAÇÃO}

Os editores do periódico Perspectivas em Gestão \& Conhecimento (PG\&C), Luciana Ferreira da Costa e Jorge de Oliveira Gomes, convidaram-me para elaborar uma apresentação da Professora Emeide Nóbrega Duarte, em virtude da entrevista concedida à PG\&C neste número.

É sempre muito difícil apresentar uma pessoa com as credenciais da Professora Emeide, pois certamente será difícil fazer jus a sua trajetória profissional, contudo, posso destacar alguns aspectos que julgo serem importantes para o leitor conhecê-la um pouco melhor.

Conheci a Professora Emeide mais de perto quando ela esteve conosco, no Programa de Pós-Graduação em Ciência da Informação da Universidade Estadual Paulista Júlio de Mesquita Filho (Unesp/Marília), para realizar seu pós-doutorado. A pesquisa desenvolvida denominada de 'Redes temáticas para cooperação em gestão da informação e do conhecimento' foi publicada posteriormente como livro. Nessa ocasião convivemos semanalmente, pois ela participava ativamente das reuniões semanais do meu Grupo de Pesquisa 'Informação, Conhecimento e Inteligência Organizacional' (GIClO), emitindo suas opiniões e compartilhando seu conhecimento aos demais membros do Grupo.

Além disso, nosso convívio também tem sido profícuo no âmbito do Grupo de Trabalho Gestão da Informação e do Conhecimento (GT-4), da Associação Nacional de Pesquisa e PósGraduação em Ciência da Informação (ANCIB), debatendo o estado da arte desta temática junto aos pesquisadores do campo científico (pares e discentes de pós-graduação).

São 23 anos dedicados à profissão e 22 anos dedicados ao ensino superior, cuja trajetória profissional evidencia a seriedade e o envolvimento em relação a construção de conhecimento no âmbito da Ciência da Informação, em especial no que se refere aos temas 'gestão da informação' e 'gestão do conhecimento'. Sua experiência profissional, produção científica e competência para a formação de pessoas, evidenciam sua importância para o avanço da área no contexto nacional.

Continue nos brindando com seus aportes teóricos e metodológicos em prol do avanço dos estudos voltados à gestão da informação e do conhecimento no contexto da Ciência da Informação.

Parabéns por sua trajetória, Emeide!

São Paulo, 04 de Agosto de 2018.

Marta Lígia Pomim Valentim

Perspectivas em Gestão \& Conhecimento, João Pessoa, v. 8, n. 2, p. 194-204, mai./ago. 2018. 


\section{GESTÃO DA INFORMAÇÃO E DO CONHECIMENTO}

Entrevista concedida pela Professora Emeide Nóbrega Duarte à Professora Luciana Ferreira da Costa e ao Professor Jorge de Oliveira Gomes em 24 de Julho de 2018.

Professora Luciana Costa - Prezada Professora Emeide, eu e o Professor Jorge Gomes gostaríamos de saudá-la, registrar a honra que é para nós entrevistá-la e nosso respeito à sua pessoa como reconhecida estudiosa brasileira da Gestão da Informação e do Conhecimento. E como primeira questão, a partir de sua formação graduada e pós-graduada, conte-nos como foi sua incursão na área da Gestão da Informação e do Conhecimento e seu fascínio por ela.

Professora Emeide - Prezados colegas, Luciana e Jorge, muito obrigada pelo convite! Como graduada em Biblioteconomia, trabalhei, inicialmente, na Secretaria de Planejamento do Estado da Paraíba como gestora da Biblioteca, durante o período de 1972 a 1975. Entre 1974 e 1975, cursei Especialização em Documentação Científica na Universidade Federal do Rio de Janeiro (UFRJ)/Instituto Brasileiro de Bibliografia e Documentação (IBBD) - atual Instituto Brasileiro de Informação em Ciência e Tecnologia (IBICT). No retorno, assumi o cargo de coordenadora da Biblioteca do Centro de Ciências Agrárias (CCA) da Universidade Federal da Paraíba (UFPB), situado no município de Areia na Paraíba. Fui sua primeira bibliotecária graduada e com o nível de Especialização. Iniciei as atividades na Biblioteca desse Centro no ano de 1975. Durante essa trajetória, cursei o Mestrado em Biblioteconomia em João Pessoa na Paraíba, no período de 1981 a 1984, e defendi a dissertação intitulada Caracterização e expectativas dos usuários da Biblioteca Juarez da Gama Batista. De volta a Areia, reassumi a coordenação da biblioteca até o ano de 1995. Durante esses 20 anos de desempenho profissional como gestora, em que tive a oportunidade de conviver com o excelente corpo docente, com os discentes e com os funcionários do CCA, agregada aos conhecimentos obtidos no Curso de Mestrado, adquiri certa experiência em gestão de unidades de informação. No ano de 1995, me aposentei, proporcionalmente, para assumir a função de docente do então Departamento de Biblioteconomia (DBD) da UFPB, atual Departamento de Ciência da Informação ( $D C l)$. Meu primeiro projeto de pesquisa versou sobre a aplicação de técnicas de marketing na Biblioteca Central da UFPB. Esse projeto foi renovado duas vezes, devido à necessidade de se estender para o endomarketing e a abordagem da cultura organizacional. Publicamos vários artigos e apresentamos diversos trabalhos em eventos, junto com os alunos bolsistas de iniciação científica (PIBIC) e os colegas engajados no projeto. Convicta de que minhas habilidades estavam definidas para a área de gestão, resolvi cursar o Doutorado em Administração, no ano de 2000, com uma proposta de pesquisa voltada para a cultura organizacional. No percurso do Doutorado, vários temas me sensibilizaram, principalmente porque estava no período em que precisava redefinir um projeto de pesquisa que atendesse mais adequadamente a minha atuação no Departamento de origem e a área de concentração do Doutorado em estratégia empresarial. Nesse período, fui presenteada pelo colega Almiro de Sá Ferreira com o livro de autoria de Jayme Teixeira Filho, Gerenciando conhecimento: como a empresa pode usar a memória organizacional e a inteligência competitiva no desenvolvimento dos negócios. Essa leitura foi o suficiente para minha incursão na área da Gestão da Informação e do Conhecimento e simpatizar com ela. De um lado, o tema contempla a administração estratégica e, outro, a Ciência da Informação. Concluí o Curso de doutorado em 2003, com a defesa da tese intitulada Análise da produção científica em gestão do conhecimento: estratégias metodológicas e estratégias organizacionais. A tese foi um sucesso, pelo menos para mim, por mostrar a relevância do ativo intangível - o conhecimento nas organizações -. Daí, então, as conexões foram sendo feitas com gestão da informação,

Perspectivas em Gestão \& Conhecimento, João Pessoa, v. 8, n. 2, p. 194-204, mai./ago. 2018. 
cultura organizacional e, mais tarde, cultura informacional, aprendizagem organizacional, competências, entre outras. Daí vieram a identificação e o fascínio pela temática. De volta ao $\mathrm{DCl}$, no ano de 2003, foi criado o Grupo de Pesquisa Informação, Aprendizagem e Conhecimento, no diretório de grupos de pesquisas do Conselho Nacional de Desenvolvimento Científico e Tecnológico (CNPq). Logo em seguida, participei da comissão para planejar o Curso de Especialização em Gestão de Unidades de Informação, do qual fui coordenadora durante o período de 2005 a 2007, que foi culminado com a publicação do livro Gestão de Unidades de Informação, em parceria com a colega e vice-coordenadora do curso, a Professora Alzira Karla Araujo da Silva. Já fascinada pelo tema, em 2010, fui indicada pela colega Isa Maria Freire para o pós-Doutorado em Ciência da Informação, por meio do Edital da Coordenação de Aperfeiçoamento de Pessoal de Nível Superior (CAPES) no 21/2009, denominado de PROCAD novas Fronteiras 2009, cuja proposta foi Rede de Cooperação e Aprendizagem na Ciência da Informação. Em consonância com a proposta, desenvolvi uma pesquisa, sob a supervisão da Professora Marta Lígia Pomim Valentim, que gerou um livro cujo título promete promover Redes temáticas para cooperação em gestão da informação e do conhecimento. Essas redes se referem à possibilidade de trabalho cooperativo que envolve a UFPB e a Universidade Estadual Paulista Júlio de Mesquita Filho (UNESP), no campo da Ciência da Informação. Ao atingir o último degrau da escala de formação acadêmica, abri as janelas para a possibilidade de expandir os conhecimentos sobre Gestão da informação e do conhecimento, por meio dos meus orientandos, como uma rede de seguidores da pesquisa voltada para consolidar o bem mais valioso do ser humano - o conhecimento - imprescindível para a inclusão em qualquer ambiente social.

Professor Jorge Gomes - Professora Emeide, diante de sua experiência e atuação profissional, de 23 anos dedicados à profissão de bibliotecária e 22 anos dedicados ao Magistério Superior, nas áreas de Biblioteconomia, Arquivologia e Ciência da Informação, quais as perspectivas e as diferenças dos estudos de Gestão da Informação e do Conhecimento na área da Ciência da Informação em relação a outras áreas, consoante a natureza interdisciplinar desses estudos?

Professora Emeide - Hoje já estou deveras ciente de que, durante o meu desempenho profissional como bibliotecária, já atuava em ações de Gestão do conhecimento, ao lembrar que mantinha um canal de informações, por meio de conversas com os docentes, e conhecia as áreas de atuação em ensino e pesquisa de cada um deles. De forma que atendia aos usuários sempre procurando conectá-los aos experts conhecedores das informações solicitadas. Essa ação é denominada por Thomas H. Davenport de uma atividade do bibliotecário como corretor do conhecimento. Ou seja, uma atividade de mediador da informação entre o usuário e o detentor de conhecimentos, como ação de mediar a informação, não só promovendo o acesso somente ao suporte formal, mas também ao informal por meio das pessoas. Isso é de uma riqueza imensa, atualmente reconhecida no ambiente das organizações. Quanto à experiência em Arquivologia, se dá em sala de aula, nos estudos e debates sobre textos aplicados, pesquisas e orientações no desempenho da atividade docente. Em relação à Ciência da Informação, a Associação Nacional de Pesquisa e Pós-Graduação em Ciência da Informação (ANCIB) tem um grupo de trabalho, o GT4 denominado de Gestão da Informação e do Conhecimento, em que as discussões já giraram visando compreender essa expressão. No período de 2004 a 2008, surgiram várias pesquisas que visavam esclarecer a origem da Gestão do conhecimento e as polêmicas a seu respeito. Como exemplos na Ciência da Informação, posso citar a tese da Professora Regina de Barros Cianconi, de 2004, e um artigo de Ricardo Rodrigues Barbosa no ano de 2008. Nessas pesquisas, os autores tentam explicar, entre outras questões, as polêmicas geradas pela natureza interdisciplinar da Gestão do conhecimento e os vários enfoques nas áreas de

Perspectivas em Gestão \& Conhecimento, João Pessoa, v. 8, n. 2, p. 194-204, mai./ago. 2018. 
Administração, Sistema de informação e Tecnologia, Ciência da Informação, Engenharia de produção, entre outras. Em revisão sistemática, intitulada Desvelando a gestão do conhecimento nos Anais do ENANCIB, as colegas Marynice Medeiros Matos Autran, Rosilene Agapito da Silva Llarena, Gabriella Oliveira e o colega Victor Pinheiro concluíram que, à medida que a Gestão do Conhecimento foi adquirindo corpo no meio acadêmico e no organizacional, o interesse pelo tema cresceu significativamente e demandou estudos, pesquisas e produção científica voltados, principalmente, para a Ciência da Informação, a área que lida diretamente com a questão da informação e do conhecimento. Esse olhar possibilita discutir sobre o tema nas mais diversas abordagens e perspectivas e enseja mais oportunidade para reflexão e consequente desenvolvimento na área de Ciência da Informação. A própria revista Perspectivas em Gestão \& Conhecimento (PG\&C) reflete sobre as diversas abordagens.

Professora Luciana Costa - Sobre a Gestão da Informação e do Conhecimento, Professora Emeide, há algo de inovador? O que podemos esperar dos novos estudos da Gestão da Informação e do Conhecimento na contemporaneidade?

Professora Emeide - Na contemporaneidade, os estudos estão tendendo a uma integração. Os autores internacionais e os nacionais já abordam a Gestão do conhecimento incluindo a Gestão da informação porque elas são integradas, como dizem os Professores Edivânio Duarte de Souza, Eduardo José Wense Dias e Mônica Erichsen Nassif, ao esclarecerem que a Gestão da informação corresponde a uma parte do processo de Gestão do conhecimento, a qual é compreendida como um estágio qualitativamente superior. $O$ historiador Peter Burke, em seu livro, O que é história do conhecimento?, ressalta a famosa metáfora de Claude Levi-Strauss "É válido pensar em informação como algo cru, e conhecimento, como algo cozido". Vale lembrar que informação não é conhecimento, mas, sem ela, não há conhecimento, porque ela é a sua base. $O$ conhecimento é construído com informações. Quanto à inovação, a própria Gestão do conhecimento já é uma abordagem inovadora. Para exemplificar, José Cláudio Terra, no livro, 10 dimensões da gestão da inovação, em sua abordagem para transformação organizacional, inclui a gestão do conhecimento e a infraestrutura tecnológica como uma entre as dez dimensões. Como as organizações buscam incessantemente novos conhecimentos, para aprimorar seus produtos e superar seus concorrentes, o investimento é nas pessoas, como incentivo à inovação, que é uma das tarefas mais importantes dos gestores do conhecimento. A literatura nacional e a internacional apresentam vários modelos de Gestão do conhecimento construídos por diversas etapas, processos ou dimensões, a maioria deles comuns, com destaque para pessoas, tecnologia e cultura organizacional. Como não existe um consenso sobre o que prevalece, há tendência para a proposição de um modelo holístico híbrido baseado no pensamento sistêmico, de forma que as aplicações se integrem em dimensões comuns baseadas nas diversas vertentes. $O$ advento de tecnologias e de novas tendências em que a informação se prolifera e, cada vez mais, dificulta a decisão sobre conteúdos confiáveis - gerou uma tarefa que exige dedicação. Assim, o conceito de Biblioteca e de Biblioteconomia tem se modificado. As bibliotecas estão migrando para novas modalidades, estão sendo chamadas de "centrais de conhecimento", são tratadas como gateways de recursos de conhecimento, centros de criação e recriação de atividades acadêmicas e, de forma similar, os bibliotecários passam a ser chamados de gerentes de conhecimento ou intérpretes de conteúdo. Ratificando esse avanço das nossas bibliotecas universitárias, a Professora Regina Célia Baptista Belluzzo, em parceria com Danielli Santos da Silva, nos brinda com a apresentação de estratégias de ação para executar um plano para transformar bibliotecas universitárias em centros de gestão do conhecimento. Entendemos essas transformações como uma inovação no âmbito de uma área em crescente desenvolvimento.

Perspectivas em Gestão \& Conhecimento, João Pessoa, v. 8, n. 2, p. 194-204, mai./ago. 2018. 
Professor Jorge Gomes - Gostaríamos que comentasse, Professora Emeide, sobre a Linha de Pesquisa Ética, Gestão e Políticas da Informação, em que a senhora atua no Programa de PósGraduação em Ciência da Informação da UFPB e leciona a disciplina Gestão: informação, conhecimento e inteligência.

Professora Emeide - Quando ingressei como docente do Programa de Pós-Graduação em Ciência da Informação (PPGCI) na linha Ética, gestão e políticas de informação, sugeri que fosse criada a disciplina Conhecimento organizacional, sempre fundamentada nas estruturas curriculares dos programas de pós-graduação em Ciência da Informação tradicionais nas abordagens em Gestão da informação e do conhecimento. Por coincidência, esses programas são os melhores pontuados pela CAPES. Além dessa inspiração, costumo acompanhar as tendências da ANCIB, no que concerne especificamente ao GT4, que, atualmente, denominase de Gestão da Informação e do Conhecimento, para inserir conteúdos pertinentes. Como se não bastasse, costumo ler e seguir os resultados de pesquisas de colegas epistemólogos da Ciência da Informação, que divulgam os resultados das tendências dos estudos na área, da forma mais honesta e ética possível, abstendo-se de manifestações pessoais, como o Professor Carlos Alberto Ávila de Araújo, por exemplo. Seguindo as orientações do PPGCl, para não se concentrar em uma única disciplina, posteriormente, sugeri a criação das disciplinas Gestão da informação e do conhecimento, Gestão: informação, conhecimento e inteligência e, atualmente, estou ministrando Tópicos Especiais em Informação, Aprendizagem $e$ Conhecimento, procurando alterná-las. Essa busca pela atualização de conteúdos para acompanhar as tendências emergentes de uma sociedade que se apresenta, ora como Sociedade da Informação, do Conhecimento e da Aprendizagem, instiga a procura desse caminho, que tem se apresentado como inatingível, considerando as limitações e as barreiras impostas pela economia mundial. Nesse PPGCl, tive a oportunidade de orientar as duas primeiras teses defendidas no ano de 2015, com diferença entre elas de 24 horas. Essas teses foram defendidas durante a realização do Encontro Nacional de Pesquisa em Ciência da Informação (ENANCIB) do mesmo ano, na cidade de João Pessoa. A motivação maior para a escolha da data foi poder contar com a participação de uma banca de nível nacional formada pelos docentes mais renomados das áreas estudadas. Contamos com as presenças dos seguintes docentes como membros externos: Marta Lígia Pomim Valentim da UNESP, Ricardo Rodrigues Barbosa da Universidade Federal de Minas Gerais (UFMG), Henriette Ferreira Gomes da Universidade Federal da Bahia (UFBA) e Luciana Moreira da Universidade Federal do Rio Grande do Norte (UFRN). Essa equipe, associada aos nossos membros da UFPB, conferiu o grau de aprovação com distinção às então doutorandas Rosilene Agapito da Silva Llarena e Raquel Rosário dos Santos, que abordaram os temas: Gestão do conhecimento e redes no Projovem urbano e Mediação da informação e do conhecimento nas bibliotecas universitárias, respectivamente. Nossa terceira orientação de doutorado aborda o tema Competências em informação dos negociadores internacionais, de autoria de Roberto Vilmar Satur. Todas as três teses foram indicadas pelo PPGCl ao prêmio ANCIB. As duas primeiras, em 2016, e a terceira está concorrendo neste ano de 2018. No momento, oriento três projetos de tese em andamento, que versam sobre comunidades de prática, inteligência competitiva e mediação da leitura para gerar conhecimento no ambiente das organizações. As três dissertações em andamento versam sobre Gestão por competências nos Cursos de Arquivologia, Memória Organizacional e Gestão da Informação e do Conhecimento na Formação do Profissional da Informação. Essa minha constância de abordagem, a pertinência e o alinhamento nas escolhas temáticas voltadas para minha área de atuação no ensino, na pesquisa e na extensão têm ocasionado algumas contrariedades, que motivam e envidam mais esforços e persistência para consolidar a gestão na linha Ética, gestão e políticas de informação do PPGCI da UFPB.

Perspectivas em Gestão \& Conhecimento, João Pessoa, v. 8, n. 2, p. 194-204, mai./ago. 2018. 
Professora Luciana Costa - Como líder do grupo de pesquisa Informação, Aprendizagem e Conhecimento (GIACO), conte-nos sua origem, suas repercussões e seus produtos, Professora Emeide.

Professora Emeide - O grupo de pesquisa Informação, Aprendizagem e Conhecimento (GIACO) foi cadastrado no diretório dos grupos de pesquisa do CNPq e certificado pela UFPB no ano de 2004. É composto de docentes, discentes, pesquisadores, técnicos e ex-alunos desvinculados da universidade, mas interessados em reingressar na educação continuada. Suas linhas de pesquisa são a Gestão da Informação e do Conhecimento e Ética, Gestão e Políticas de Informação. Os temas abordados são sobre aprendizagem organizacional, cultura informacional, comunidade de práticas, competência em informação, inteligência organizacional, entre outros relacionados à gestão da informação e do conhecimento, considerando o leque abrangente dessa abordagem. Embora os integrantes do GIACO fossem sempre motivados pela busca de novos conhecimentos e pela chance de concorrer a processos de seleção para ingressar em cursos de pós-graduação, percebia-se a existência de algumas dificuldades que impediam o grupo de atingir resultados mais satisfatórios. Para contornar as fragilidades e aproveitar suas fortalezas, assim como conhecer as oportunidades e as ameaças do ambiente, foi adotada a análise SWOT, cujos resultados estão relatados nos estudos sob a autoria de Sabrina Bezerra Leal, em desenvolvimento de projeto de iniciação científica e trabalho de conclusão do Curso de Biblioteconomia, sob minha orientação. Essa reflexão realizada coletivamente trouxe vários benefícios para o Grupo. Os pontos evidenciados foram relacionados às práticas da produção científica, à disseminação de informações e de conhecimentos, à participação em eventos da área, ao acesso à literatura pertinente de nível internacional, à promoção do processo de criatividade e de geração de ideias e a perfeita comunicação entre os membros do grupo, entre outras questões. Atualmente, durante os encontros do GIACO, são discutidos aspectos teóricos e práticos relacionados aos temas compatíveis com as linhas. Os integrantes desenvolvem projetos de pesquisa, debatem sobre textos de autores clássicos, publicam artigos em eventos, em periódicos e demais meios de comunicação científica, de forma colaborativa, e promovem a produção e a disseminação de novos conhecimentos. O GIACO mantém intercâmbio com outras instituições em âmbito internacional, nacional, estadual, interinstitucional e intrainstitucional. Como destaque para o relacionamento interpessoal existente, seus membros sabem aceitar as críticas construtivas e transformá-las em lições aprendidas. Além de usufruir de um espaço físico onde acontecem as reuniões presenciais, o grupo se comunica pela rede social Whatsapp, que propicia a interação de seus aprendentes para que possam falar sobre assuntos relacionados ao planejamento de reuniões, tratar de relações interpessoais, de comemorações de aniversários, indicações de leituras, entre outros. Dispõe de um blog para divulgar as atividades realizadas, como eventos e informações relevantes para essa comunidade de aprendizagem, por meio dos temas de interesse. Entre os produtos, constam a publicação de livros, coletâneas, e-books, artigos publicados em periódicos, trabalhos publicados em eventos, mesas redondas, palestras, workshop, reuniões, leituras e debates interativos de textos inovadores. $O$ trimestre referente aos meses de maio, junho e julho deste ano foi dedicado à realização do I Workshop do GIACO e à produção de artigos para serem submetidos nos eventos do Encontro da Associação de Educação e Investigação em Ciência da Informação de Iberoamérica e Caribe (EDICIC), do Congresso Nacional de Arquivologia (CNA), do ENANCIB e do Congresso Nacional de Gestão do Conhecimento (KM Brasil). No momento, os membros do grupo, especialmente, os autores e os coautores, estão aguardando os resultados com ansiedade gerada pela vontade de participar. 
Professor Jorge Gomes - Poderia nos contar como foi sua experiência e quais os desafios à frente da Coordenação do Grupo de Trabalho (GT) 4 - Gestão da Informação e do Conhecimento, e, atualmente, da Vice-Coordenação deste GT, da Associação Nacional de Pesquisa e Pós-Graduação em Ciência da Informação (ANCIB)?

Professora Emeide - No ano de 2012, fui consultada e estimulada pela colega Professora Sueli Angélica do Amaral, coordenadora em exercício, e logo em seguida, convidada pelos pares mais assíduos aos encontros do GT4 para assumir esta Coordenação, junto com a colega Alzira Karla Araújo da Silva, como vice-coordenadora. Confesso que fiquei bastante honrada pela confiança depositada e pela oportunidade de ficar mais inteirada das questões que envolvem o desenvolvimento da área com que me identifico, na tentativa de colaborar para seu crescimento, por acreditar que estava no caminho certo. Durante o ano de 2013, a temática geral do ENANCIB foi Informação e interação: ampliando perspectivas para o desenvolvimento humano. $\mathrm{O}$ envolvimento com as atividades demandadas por essa temática foi substancial. Para acompanhá-lo, propus um estudo intitulado $O$ fluxo da informação e aprendizagem em evento científico, desenvolvido em parceria com os docentes Alzira Karla Araújo da Silva e Alexandre Nóbrega Duarte. O objetivo foi de conhecer a opinião da comunidade científica para contribuir com a melhoria constante da realização do evento em pauta, por meio do contato com as pessoas envolvidas em suas atividades, na perspectiva dos autores, dos avaliadores e dos coordenadores sobre o fluxo de informações durante as fases de realização do evento, para viabilizar uma aprendizagem contínua no ambiente. O GT4 apresentou 33 trabalhos científicos, bem característicos e representativos da temática geral, na perspectiva da gestão da informação e do conhecimento nas organizações, como contribuição para a Ciência da Informação. No ano de 2014, continuando as atividades de coordenação, no ENANCIB, com a temática geral Além das Nuvens: expandindo as fronteiras da Ciência da Informação, o GT 4 fez jus à temática com a apresentação de 37 trabalhos de alto nível em contribuição à expansão dos trabalhos sobre Gestão da informação e do conhecimento nas organizações. Devido à ampliação da abordagem sobre Gestão da informação e do conhecimento para outros ambientes, o GT4 mudou para Gestão da informação e do conhecimento. Por ocasião da realização do ENANCIB do ano de 2016, a Professora Alzira Karla Araújo da Silva foi indicada para coordenar o GT4, e meu nome foi cogitado para ser vice-coordenadora. Aceitei porque me identificava com a área e por causa da afinidade com o trabalho desenvolvido em parceria e cooperação com a nova coordenadora ao longo dos anos. Essa experiência está sendo enriquecedora e aprendi que dedicação, bom senso, respeito e responsabilidade são ingredientes para vencer os desafios da convivência humana.

Professor Luciana Costa - Professora Emeide, qual a experiência de receber os Prêmios de Melhor Trabalho do GT 4 - Gestão da Informação e do Conhecimento da ANCIB por três vezes, nos anos de 2011, 2016 e 2017, e orientar o eleito Melhor Trabalho de Conclusão de Curso do Prêmio da Associação Brasileira de Educação em Ciência da Informação ( $A B E C I N$ ) no ano de 2017?

Professora Emeide - A experiência de receber um prêmio de melhor trabalho é bastante compensadora, considerando que eles foram elaborados em parceria com os orientandos ou colegas que trabalham comungando pensamentos, desprendendo esforços e, principalmente, de forma harmoniosa, com a intenção de oferecer o melhor de si em busca de sucesso. A primeira intenção é de alcançar a aprovação do trabalho para socializar de forma oral e escrita. Não almejo premiação, mas se vier, será bem-vinda. Um dos trabalhos premiados no ano de 2011 intitula-se Dimensões de um modelo de gestão da informação no campo da Ciência da Informação: uma revelação da produção científica do $E N A N C I B$, fruto da dissertação de autoria

Perspectivas em Gestão \& Conhecimento, João Pessoa, v. 8, n. 2, p. 194-204, mai./ago. 2018. 
de Irma Gracielle Souza. Fiquei muito feliz, como orientadora e coautora, considerando que foi fruto da minha primeira orientação em nível de pós-graduação. Como premiação, tivemos a publicação no periódico científico Liinc em revista. Em 2016, foi premiado no GT-4 o trabalho Atividades de gestão nos dispositivos de comunicação da web social das bibliotecas universitárias brasileira, sob a coordenação do colega Ricardo Rodrigues Barbosa, que é parte da tese da minha ex-orientanda, Raquel Rosário dos Santos, do qual sou coautora. Essa premiação foi recebida com muita alegria, devido à contribuição dessa pesquisa para inovar as bibliotecas universitárias brasileiras. A premiação merecida foi reconhecida com a publicação na Revista Tendências da Pesquisa Brasileira em Ciência da Informação. Em 2017, um dos trabalhos premiados foi Estudo terminológico do termo gestão do conhecimento, realizado pela autora Rosilene Agapito da Silva Llarena, que contou com minha coautoria e as de Suzana Lucena Lira e Alzira Karla Araújo da Silva. Nesse ano, o GT4 estava sob a coordenação da colega Alzira Karla Araújo da Silva e minha atuação como vice-coordenadora. Esse trabalho foi publicado na revista Tendências da Pesquisa Brasileira em Ciência da Informação em junho de 2018. Foi muito bem vinda a premiação, pois o conteúdo do trabalho foi oferecido com muito carinho aos colegas da Ciência da Informação, em especial, e aos demais leitores, como mais uma tentativa de esclarecer o significado do fenômeno denominado Gestão do conhecimento para dirimir as inquietações. Convém explicar que esse trabalho foi avaliado por uma comissão especial durante o ENANCIB, para evitar ingerência dos coordenadores dos GTs sobre trabalhos de suas autorias. Portanto, em momento algum, considero comportamento antiético por entender que as pesquisas foram realizadas em coautorias e não cabe a mim, como coautora, cercear o direito dos parceiros de serem reconhecidos como premiados e, evidentemente, motivados a novas contribuições científicas. Em relação ao prêmio como orientadora do Melhor Trabalho de Conclusão do Curso de Arquivologia do Prêmio da Associação Brasileira de Educação em Ciência da Informação (ABECIN) no ano de 2017, no âmbito do Nordeste, foi uma surpresa bastante agradável. Intitulado $A$ interface entre $a$ memória organizacional e a gestão do conhecimento, de autoria de Rayan Aramís de Brito Feitoza, foi publicado no periódico científico Àgora, uma revista do Curso de Arquivologia da Universidade Federal de Santa Catarina (UFSC). Essa premiação resultou em frutos inestimáveis ao autor, devido ao incentivo para aprofundar o estudo rumo ao Mestrado e ao Doutorado. Premiações como as mencionadas são salutares na vida acadêmica dos orientandos, porque os estimulam a continuar os estudos, ao vislumbrarem novas conquistas profissionais. E do lado do orientador, reativa o sentimento de pertencer à Academia e provoca o estímulo por mais trabalhos e, em casos específicos, adiar a aposentadoria.

Professor Jorge Gomes - Como a senhora percebe, Professora Emeide, o panorama formativoprofissional do Brasil sobre instituições dedicadas à Gestão da Informação e do Conhecimento, como a Sociedade Brasileira de Gestão do Conhecimento (SBGC) e Programas de Pósgraduação em Administração, Ciência da Informação, Engenharia e Gestão do Conhecimento e, mais recentemente, promovido pela Universidade Federal de Minas Gerais (UFMG), em Gestão e Organização do Conhecimento, em sua relação com o panorama internacional?

Professora Emeide - A Sociedade Brasileira de Gestão do Conhecimento (SBGC), fundada em 2001, é qualificada como Organização da Sociedade Civil de Interesse Público (OSCIP). Entre outras programações, é responsável pela realização do Congresso Brasileiro de Gestão do Conhecimento - KM Brasil. Neste ano de 2018, vai acontecer a 14a edição do Congresso que iniciou no ano de 2004. Tenho acompanhado as publicações do evento e percebo a evolução dos estudos em Gestão do conhecimento ao longo dos anos e a contribuição que têm dado à Academia, que cada dia se envolve mais com a participação dos pesquisadores docentes e discentes. Ao revisitar os doze melhores trabalhos do Congresso no ano de 2016, publicados 
na PG\&C, chamou-me atenção o artigo intitulado Tipologia do trabalhador do conhecimento: papéis e processos, de autoria de Valéria Macedo (doutoranda em Ciência da Informação pelo IBICT), Neusa Maria Bastos Fernandes dos Santos (Doutora em Controladoria e Contabilidade pela Universidade São Paulo), João Belmiro do Nascimento (Doutor em Comunicação e Semiótica pela Pontifícia Universidade Católica de São Paulo) e André Saito, Doutor em Ciências do Conhecimento pelo Japan Advanced Institute of Science and Technology, no Japão, e Presidente da SBGC. Essa pesquisa apresenta, entre as ações que os trabalhadores do conhecimento realizam durante suas tarefas: a) Aquisição: buscar conhecimento, nos meios de informação, com o objetivo de desenvolver habilidades, estruturar um projeto ou obter um objeto; b) Busca de informação: procurar informações sobre tópicos específicos de uma forma específica, utilizando sempre uma estrutura de pastas em um sistema ou um sistema de recuperação da informação; c) Busca de informação especializada: recorrer a um especialista para discutir e encontrar soluções para um problema específico; d) Organização de informação: organizar informações pessoais e organizacionais; e) Disseminação: compartilhar informações ou objetos/conteúdos, sempre sobre resultados obtidos no trabalho; f) Feedback: avaliar uma proposta ou o conteúdo da informação e; g) Networking: interagir com outras pessoas e organizações para trocar informações e desenvolver relacionamentos. Os resultados me alegraram porque esses processos são da competência dos profissionais da informação. Há poucos meses, o presidente da SBGC, André Saito, entrevistou a gestora de conhecimento da empresa Petrobrás, com graduação em Biblioteconomia e Mestrado em Ciência da Informação. Isso tudo é muito estimulante e abre um novo mercado para os nossos alunos no campo da Ciência da Informação (Biblioteconomia e Arquivologia). Entre as instituições de ensino superior que se dedicam aos estudos de Gestão da informação e do conhecimento, a plataforma sucupira registra o Mestrado Profissional em Gestão do Conhecimento e Tecnologia da Informação, na Universidade Católica de Brasília; Doutorado e Mestrado em Engenharia e Gestão do Conhecimento na UFSC; Doutorado em Difusão do Conhecimento na UFBA; Mestrado Profissional em Sistemas de Informação e Gestão do Conhecimento na Fundação Mineira de Educação e Cultura (FUMEC) em Minas Gerais; Mestrado Profissional em Gestão do Conhecimento nas Organizações, no Centro Universitário de Maringá, Paraná; Gestão da Informação e do Conhecimento na UFRN; Mestrado e Doutorado em Informática e Gestão do Conhecimento na Universidade Nove de Julho, e Mestrado e Doutorado em Gestão \& Organização do Conhecimento na UFMG . A criação de cursos de gestão do conhecimento em nível pós-graduação stricto sensu demonstra que é preciso fomentar pesquisas sobre o tema, que possam propor soluções técnico-científicas para a gestão orientada ao conhecimento, pois ampliar o estudo e a pesquisa sobre essa temática é importante e essencial para a sociedade contemporânea. Quando se analisa a gestão do conhecimento, observa-se que suas abordagens podem ser divididas em dois grupos principais: a Gestão do Conhecimento, como assunto relativo à $\mathrm{Tl}$, e a Gestão do Conhecimento, mais voltada para o desenvolvimento dos recursos humanos. Analisando essas duas frentes, vê-se que a Gestão do Conhecimento não é restrita a uma área de conhecimento. Esse é um dos motivos pelo qual é uma disciplina muito favorável a uma abordagem interdisciplinar. No estudo bibliométrico, em nível internacional, realizado por Roberta Moraes Bem e Christianne Coelho de Souza Renisch, as temáticas abordadas - Biblioteconomia e/ou Ciência da Informação e Gestão do Conhecimento - parecem estar associadas e ser interdependentes, na medida em que trabalham com a informação e o conhecimento e se desenvolvem dentro de um ciclo que transforma dado em informação, informação em conhecimento e conhecimento em sabedoria em um ciclo intermitente. Ainda, como resultados de pesquisa, em relação aos dezessete títulos de periódicos mais produtivos em nível internacional, os mais presentes foram o periódico Library \& Information Update e o Journal of Information Science. Nessa análise, estão presentes dois periódicos nacionais: Perspectivas em Ciência da Informação e 
Informação e Sociedade: estudos. Essas evidências me deixam mais segura de que estou no caminho certo, na tentativa de cooperar para consolidar a Gestão da Informação e do Conhecimento na Ciência da Informação.

Professora Luciana Costa - Professora Emeide, eu e Professor Jorge agradecemos muitíssimo por sua presteza em responder a esta entrevista, brindando-nos com sua expertise e competência em Gestão da Informação e do Conhecimento, advindas de seu capital intelectual. Sendo assim, deixamos o espaço aberto para suas últimas considerações.

Professora Emeide - Agradeço pela oportunidade de poder expor e declarar minha "paixão" pela Gestão da Informação e do conhecimento desde o ano de 2000, principalmente por ter sido registrada neste diálogo com os idealizadores e dirigentes da revista Perspectivas em Gestão \& Conhecimento - PG\&C. Parabenizo os dois colegas por essa iniciativa da PG\&C, que veio na hora certa, em que a produção científica, essencialmente em gestão do conhecimento, estava tomando espaço e robustez. A perspectiva integradora entre Ciência da Informação e Administração no Centro de Ciências Sociais Aplicadas da UFPB para realização da revista foi muito inteligente, tendo em vista que são os campos que mais dialogam entre si, de forma interdisciplinar e enriquecedora pela consagração da informação como elemento central dessa aproximação. A informação, objeto de estudo da Ciência da Informação, é considerada na Administração como recurso organizacional que gera valor produtivo e de capital para as organizações. É o elo que constitui matéria-prima para informar e para administrar sua aplicação. Esse convite me deixou muito honrada. Obrigada de coração.

\section{AGRADECIMENTOS}

À Professora Emeide Nóbrega Duarte por nos conceder a honra desta entrevista e por nos permitir conhecer a sua importante trajetória profissional que marcam a sua larga experiência como docente e pesquisadora acerca da Gestão da Informação e da Gestão do Conhecimento.

À Professora Marta Lígia Pomim Valentim que, gentil e prontamente, aceitou elaborar a apresentação desta entrevista.

João Pessoa, Brasil, 29 de Agosto de 2018.

Luciana Ferreira da Costa e Jorge de Oliveira Gomes

Perspectivas em Gestão \& Conhecimento, João Pessoa, v. 8, n. 2, p. 194-204, mai./ago. 2018. 